\title{
HASHTAG POPULARITY INDEX (HPI): ELIMINASI SPAM DI HASHTAG
}

\author{
Yumarsono Muhyi', Said Mirza Pahlevi \\ ${ }^{1}$ Jurusan Sistem Komputer, STMIK Indonesia Jakarta \\ ${ }^{2}$ Badan Pusat Statistik, Jakarta \\ muhyi@stmik-indonesia.ac.id'1 ${ }^{1}$ smirza@bps.go.id ${ }^{2}$
}

\begin{abstract}
Abstrak
Twitter yang menjadi sistem media sosial yang sangat populer saat ini, mengundang para spammer untuk mengekspliotasinya. Salah satu teknik spam yang paling sering dilakukan di Twitter adalah dengan membanjiri Twitter dengan posting tweet yang sangat banyak dan memasang hashtag yang sedang trending dengan jumlah yang banyak. Artikel ini memberikan sebuah metode baru bernama Hashtag Popularity Index (HPI), yang mampu mengeliminasi spam pada hashtag dan ekspliotasi hashtag. Dengan menggunakan fitur-fitur internal dari tweet, HPI dapat digunakan dan diimplementasikan sebagai alat yang handal dan robust dalam mengeliminasi spam pada hashtag.
\end{abstract}

Kata Kunci: hashtag, rekomendasi, spam, tweet, seleksi

\section{Abstract}

Twitter currently has become one the most popular social media system, is tempting spammers to exploit it. One of the spam technique being conducted in Twitter is by flooding Twitter with large amount of tweets and by putting many trending hashtags. This article gives a novelty named Hashtag Popularity Index (HPI) which is able to eliminate spams in hashtags and hashtag exploitation. Using internal features of tweets, HPI is suitable to use and to implement as a reliable and robust tool in eliminating spams in hashtag.

Keywords: hashtag, recommendation, spam, tweet, selection

\section{Pendahuluan}

Twitter adalah salah satu dari sistem media sosial daring (dalam jaringan atau online) yang terpopuler saat ini. Twitter memiliki 313 juta akun pengguna yang aktif tiap bulannya dan selalu ada 500 juta pesan tweet baru setiap harinya [3].

Pada Juni 2012, lebih dari 500 juta akun pengguna terdaftar di Twitter, dengan Indonesia menduduki urutan ke-5 terbanyak di seluruh dunia untuk pengguna Twitter. Jakarta adalah kota teraktif dalam membuat posting di Twitter dengan lebih dari 24,3 juta tweet publik yang dikirimkan oleh para pengguna Twitter di Jakarta setiap harinya [8]. Untuk mempermudah pencarian tweet, seorang pembaca tweet disarankan memilih pesan-pesan tweet dengan menggunakan hashtag untuk membuang tweet yang tidak diinginkan. Sebagai hasilnya, bagi para penulis tweet, memilih hashtag yang tepat agar dapat meraih para pembaca yang ditujunya [11].

Popularitas Twitter yang tinggi ini mengundang para spammer untuk melakukan posting bersifat spam demi berbagai tujuan. Pada tahun 2014 ditengarai tidak kurang dari 8,5\% akun pengguna Twitter (atau setara dengan 23 juta akun pengguna) yang diduga sebagai spammer, yang dicirikan dengan kegiatan mereka yang sangat rutin dan terpola [3]. Karena hashtag menjadi alat bagi Twitter untuk menetapkan trending topics, maka hashtag pun menjadi sarana ideal bagi para spammer untuk melancarkan kegiatan spamming mereka [9].
Karena hashtag merupakan sarana indeks utama dalam pesan-pesan tweet, maka hashtag tetap digunakan. Artikel ini bertujuan memberikan metode baru dalam menyaring spam dalam pencarian hashtag, agar hashtag tetap dapat berfungsi secara objektif dan optimal sesuai tujuan asalnya. Metode baru ini bernama Hashtag Popularity Index (HPI) yang dapat menyaring spam pada hashtag dengan sangkil (efektif) dan mangkus (efisien).

\section{Penelitian Terkait}

\subsection{Rekomendasi Hashtag}

Hashtag disarankan untuk digunakan oleh Twitter sebagai alat bantu bagi Twitter untuk mengindeks pesan-pesan tweet. Pemilihan hashtag yang digunakan memiliki algoritma heuristis tertentu yang disarankan oleh Twitter [11]. Pada umumnya penelitian-penelitian untuk merekomendasikan hashtag menggunakan metode supervised (clustering yang menggunakan masukan dari luar tweet) $[1,4,5,12]$, unsupervised (klasifikasi yang menggunakan fitur-fitur internal dari tweet) [2,6,7], atau merupakan gabungan keduanya (hybrid atau semi-supervised).

\subsection{Pengaruh Spam di Rekomendasi Hashtag}

Penelitian [9] menunjukkan bahwa adanya spam di Twitter memiliki pengaruh cukup dominan dalam mengganggu proses rekomendasi hashtag pada tweet. 
Pada penelitian ini diperoleh bahwa hashtag pada spam tweet memiliki akurasi rekomendasi lebih tinggi daripada pesan-pesan tweet yang benar (ham tweet).

Hal ini berarti bahwa suatu tweet akan berpeluang lebih tinggi mendapatkan rekomendasi hashtag yang tergolong spam daripada yang benar. Untuk meningkatkan peluang rekomendasi hashtag yang benar (non-spam) pada ham tweet ini, maka efek spam tweet ini perlu disaring dan dihilangkan.

\subsection{Metode Deteksi Spam di Twitter}

Penelitian [3] memaparkan metode-metode yang umum digunakan dalam deteksi spam di Twitter, dengan menggunakan fitur-fitur Twitter berikut.

1. Akun dari tweet

2. Isi pesan tweet

3. Grafik relasi antara tweet dan akun

4. Gabungan atau campuran (hybrid) dari beberapa fitur

Penelitian ini juga memaparkan hal-hal yang digunakan Twitter dalam mendeteksi spam.

1. Posting tweet yang serupa dengan sangat banyak, baik di multi-akun atau di akun tunggal;

2. Melakukan follow atau unfollow dalam jumlah besar dan dalam rentang waktu singkat;

3. Memiliki laporan spam yang sangat banyak atas akun tersebut;

4. Sangat agresif dalam melakukan like, follow, dan retweet;

5. Memasukkan tautan (link) yang malicious (cenderung berbahaya);

6. Melakukan posting tweet yang isinya kebanyakan adalah tautan, bukan update status personal;

7. Melakukan posting tweet ke sebuah trending topic, untuk melacak sistem deteksi spam apa yang sedang dilakukan.

Penelitian [10] mengungkapkan bahwa salah satu hal utama yang juga menjadi ciri spammer adalah mereka melakukan eksploitasi hashtag dengan masif. Sebanyak $76 \%$ ham tweet tidak memiliki hashtag dan 97\% ham tweet memiliki maksimum 2 buah hashtag. Sebaliknya, sebanyak $40 \%$ spam tweet memiliki 3 buah hashtag atau lebih dan hanya $37 \%$ yang tidak memiliki hashtag.

Penelitian [3] melakukan deteksi spam berdasarkan fitur-fitur yang kebanyakan terkait hal eksternal dari suatu tweet. Hal ini menyulitkan pelacakan spam tweet secara sederhana dan cepat. Dari penelitian [3] ini hanya poin pertama yang merupakan fitur internal dari tweet, yaitu bahwa spammer akan melakukan posting tweet dengan jumlah yang sangat besar.
Sementara dari penelitan [10] diperoleh hubungan sederhana antara hashtag dengan tweet yang berkategori spam dan ham, yang dapat digunakan sebagai pelacakan spam tweet secara sederhana dan cepat. Dari penelitian [10] ini dapat diperoleh hubungan antara ham tweet dengan spam tweet, berupa rasio dari jumlah hashtag antara keduanya itu sebagai berikut.

1. Tanpa hashtag $=76: 37=2,1: 1$

2. Maksimal 2 hashtag $=97: 60=1,6: 1$

3. Lebih dari 2 hashtag $=3: 40=1: 13,3$

Dari sini dapat ditarik kesimpulan sederhana bahwa tweet yang memiliki lebih dari 2 buah hashtag memiliki peluang dikategorikan sebagai spam tweet sebesar 13,3 kali lebih tinggi daripada ham tweet. Jumlah hashtag lebih dari dua inilah yang akan digunakan sebagai indikasi awal dan cepat, bahwa sebuah tweet adalah spam atau ham.

\section{Hashtag Popularity Index (HPI)}

HPI merupakan metode penyaringan hashtag spam yang bersifat campuran (hybrid), dengan mengambil fitur-fitur tweet dari akun dan dari isi pesannya, untuk digunakan dalam kalkulasi.

\subsection{Ekstraksi Fitur-Fitur Twitter}

Dimisalkan $T$ adalah kumpulan tweet dalam corpus (himpunan atau set dokumen) yang akan dianalisis dan $H$ adalah himpunan hashtag unik yang telah diekstraksi dari semua tweet di T. Setiap tweet pada $T$ dapat memiliki hashtag $h$ sejumlah nol (0) atau lebih yang bersifat unik. Pemetaan (mapping) ini secara matematis dinotasikan sebagai $m(t, h) \in$ $\{0,1\}$, fungsi ini bernilai 1 jika tweett memiliki hashtag $h$ dan 0 jika tidak.

Dinotasikan $U$ adalah himpunan akun pengguna (user) yang terdapat dalam corpus, maka $o(t, u) \in$ $\{0,1\}$ adalah fungsi kepemilikan (ownership) dari tweet, bernilai 1 jika tweett dimiliki akun $u$ dan 0 jika tidak. Notasi berikutnya $f_{u}$ adalah jumlah follower (pengikut) dari akun $u$.

Kemudian dirumuskan jumlah reader (pembaca) dari akun $u$ adalah $r_{u}=f_{u}+1$, yang berarti bahwa semua tweet yang dibuat oleh $u$ akan dibaca oleh semua follower $u$ dan $u$ sendiri. Lalu dirumuskan jumlah pembaca dari hashtagh adalah nilai maksimum dari jumlah pembacanya, yang dinotasikan sebagai berikut.

$$
r_{h}=\max \left(m(t, h) \times o(t, u) \cdot r_{u}\right)
$$

\subsection{Formulasi HPI}

HPI bertujuan untuk melakukan penyaringan spam di hashtag, dengan cara menghilangkan beberapa faktor dari spam.

1. Posting tweet yang sangat banyak [3] dari akun spammer; 
2. Menggunakan hashtag dengan sangat masif [10] dari akun spammer.

Faktor posting tweet yang sangat banyak ini dieliminasi dengan rumus User-Tweet Ratio (UTR) untuk setiap hashtag, yaitu jumlah akun total di corpus dibagi dengan jumlah tweet untuk hashtag tersebut. Dengan UTR ini diperoleh bahwa semakin banyak tweet yang yang menggunakan suatu hashtag, maka nilainya akan semakin rendah. UTR dinotasikan sebagai berikut.

$$
U T R_{h}=\frac{|U|}{\sum^{h} m(t, h)}
$$

Faktor eksploitasi hashtag dieliminasi dengan formula Hashtag-User Support (HUS), yaitu jumlah akun untuk hashtag tersebut dibagi dengan total akun di corpus. Dengan HUS ini semakin besar pengguna suatu hashtag, maka semakin tinggi pula nilainya. HUS itu dinotasikan sebagai berikut.

$$
H U S_{h}=\frac{\sum^{h}(m(t, h) \times o(t, u))}{|U|}
$$

Kedua rumus untuk mengeliminasi faktor eksploitasi hashtag ini digabungkan menjadi User Ratio (UR) per hashtag dapat dihitung menggunakan

$$
U R_{h}=U T R_{h} \cdot H U S_{h}
$$

atau menjadi

$$
U R_{h}=\frac{\sum^{h}(m(t, h) \times o(t, u))}{\sum^{h} m(t, h)}
$$

Elimininasi faktor pembaca dari spam adalah dengan mengambil nilai logaritma dari $r_{h}$, yang kemudian hasilnya digabungkan dengan $U R_{h}$ untuk mendapatkan nilai HPI, menjadi formula berikut.

$$
H P I_{h}=U R_{h}
$$

\section{Percobaan dan Hasil}

Percobaan dilakukan dengan mengambil corpus dari Twitter yang berbahasa Indonesia saja, dari 12 Juni 2016 sampai 18 Juni 2016, dengan mengambil tweet yang berasal dari area geografis Indonesia. Dari pengambilan data diperoleh 332.000 tweet, dan hanya 207.153 tweet yang benar-benar menggunakan Bahasa Indonesia.

Dari sini diperoleh 28.543 tweet yang memiliki hashtag di dalam teksnya, dan inilah yang dijadikan corpus. Total terdapat 18.049 hashtag yang dipetakan ke dalam 51.034 tweet. Dari data ini, diperoleh 10 hashtag dengan frekuensi tertinggi sebagai berikut.

1. \#pathdaily: 1069 tweet

2. \#dimanamacetid: 606 tweet

3. \#latepost: 584 tweet

4. \#np: 471 tweet
5. \#kom8: 457 tweet

6. \#jakarta: 374 tweet

7. \#prillyatgemaramadhansctv: 348 tweet

8. \#bukabarenguyatrans7ke15: 310 tweet

9. \#ramadhan: 283 tweet

10. \#bukber: 246 tweet

Dari seluruh 28.543 tweet, yang terindikasi sebagai spam ada sebanyak 4.778 tweet (16,7\%), karena memiliki lebih dari 2 hashtag, dengan jumlah maksimumnya adalah 12. Dari sepuluh hashtag dengan frekuensi tertinggi, total spam tweet berjumlah 1.622 dan rata-rata tertimbang (weighted average) spam adalah $76,08 \%$, dengan jumlah spam dan porsi spam per masing-masing hashtag adalah sebagai berikut.

1. \#pathdaily: 4 dan $0,37 \%$

2. \#dimanamacetid: 606 dan $100 \%$

3. \#latepost: 181 dan $30,99 \%$

4. \#np: 156 dan 33,69\%

5. \#kom8: 0 dan 0\%

6. \#jakarta: 364 dan $97,33 \%$

7. \#prillyatgemaramadhansctv: 16 dan $4,68 \%$

8. \#bukabarenguyatrans 7ke15: 0 dan 0\%

9. \#ramadhan: 157 dan 55,48\%

10. \#bukber: 138 dan $56,10 \%$

Setelah dilakukan eliminasi spam dengan HPI, diperoleh 10 hashtag tertinggi sebagai berikut.
1. \#pathdaily: HPI $=0,26989013$
2. \#latepost: HPI $=0,19814547$
3. \#bukber: $\mathrm{HPI}=0,09700476$
4. \#ramadhan: HPI $=0,05199094$
5. \#likeforlike: $\mathrm{HPI}=0,04496257$
6. \#euro2016: HPI = 0,03847262
7. \#bukabarenguyatrans7ke15: HPI = 0,02946414
8. \#repost: HPI $=0,02889165$
9. \#eng: HPI $=0,02579069$
10. \#like4like: HPI = 0,02566204

Dari kesepuluh hashtag setelah HPI ini, total spam tweet berjumlah 779 dan rata-rata tertimbang spam adalah $49,91 \%$. Di sini terlihat bahwa setelah HPI spam tweet telah berhasil direduksi dan eksploitasi hashtag oleh spammer juga telah berhasil direduksi dengan sangat baik. Jumlah spam dan porsi spam per masing-masing hashtag adalah sebagai berikut.

1. \#pathdaily: 4 dan $0,37 \%$

2. \#latepost: 181 dan $30,99 \%$

3. \#bukber: 138 dan 56,10\%

4. \#ramadhan: 157 dan $55,48 \%$

5. \#likeforlike: 93 dan $71,54 \%$

6. \#euro2016: 61 dan 34,46\%

7. \#bukabarenguyatrans 7ke15: 0 dan 0\%

8. \#repost: 18 dan $8,7 \%$

9. \#eng: 41 dan $32,03 \%$

10. \#like4like: 86 dan 79,63\% 


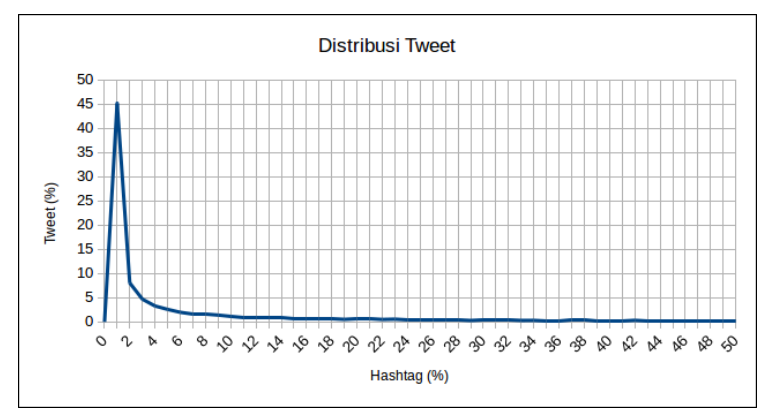

Gambar 1. Distribusi Hashtag Sebelum HPI

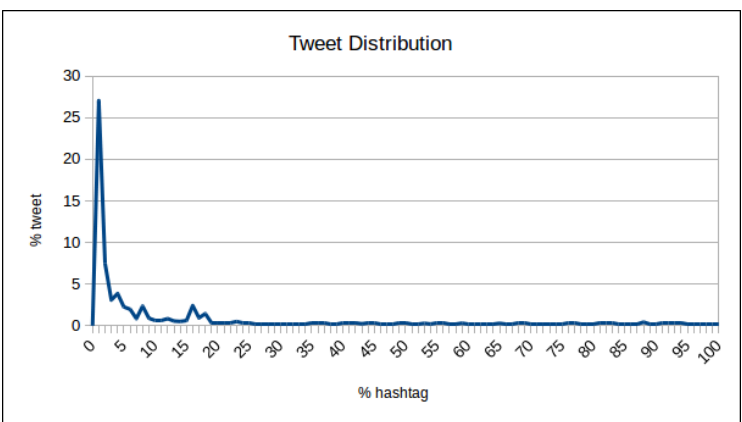

Gambar 2. Distribusi Hashtag Setelah HPI

Distribusi hashtag terhadap prosentase tweet sebelum HPI ditampilkan pada Gambar 4.1. Dari gambar tersebut terlihat tingkat short head yang tinggi, yaitu $50 \%$ distribusi tweet tercapai hanya dengan $2 \%$ hashtag dengan frekuensi tertinggi pertama.

Distribusi hashtag terhadap prosentase tweet setelah dilakukan eliminasi spam dengan HPI ditampilkan pada Gambar 4.2. Distribusi tweet setelah dilakukan eliminasi spam dengan HPI megalami koreksi derajat short head yang cukup signifikan, dimana $50 \%$ tweet tertinggi pertama dicapai untuk hashtag tertinggi pertama sebanyak $10 \%$.

\section{Kesimpulan}

HPI yang diajukan pada artikel ini secara tepat dapat mengeliminasi spam pada hashtag dari dua faktor utama serangan spam sebagai berikut.

1. Posting tweet yang sangat banyak dari para spammer [3], yang eliminasinya ditandai dengan menurunnya spam tweet yang terlibat dalam hashtag rekomendasi, dari 1.662 menjadi 779 .

2. Mengekspliotasi hashtag dengan sangat masif [10], yang eliminasinya ditandai dengan penurunan nilai rata-rata tertimbang porsi spam dari hashtag rekomendasi, dari yang awalnya $76,08 \%$ menjadi $49,91 \%$.
Dengan HPI ini, sistem rekomendasi hashtag yang disarankan oleh Twitter [11] dapat tetap dijalankan dengan konsistensi hashtag yang tinggi. Kalkulasi HPI ini dapat diimplementasikan dengan cepat dan robust, karena hanya mengambil fitur-fitur tweet yang internal dan inheren pada tweet itu sendiri, tanpa perlu intervensi dari fitur eksternal.

\section{Daftar Pustaka}

[1] Dovgopol, R., Nohelty, M., "Twitter Hash Tag Recommendation", Computing Research Repository, 2015.

[2] Godin, F., Slavkovikj, V., Neve, W.D., Schrauwen, B., Walle, R.V., "Using Topic Models for Twitter Hashtag Recommendation. Proceedings of the 22nd International Conference on World Wide Web", ACM, 2013.

[3] Kabakus, A.T., Kara, R., "A Survey of Spam Detection Methods on Twitter", (IJACSA) International Journal of Advanced Computer Science and Applications, 2017.

[4] Kywe, S.M., Hoang, T.A., Lim, E.P., Zhu, F. “On Recommending Hashtags in Twitter Networks. Proceedings of the 4th International Conference on Social Informatics", Berlin: Springer-Verlag, 2012.

[5] Mazzia, A., Juett, J. "Suggesting Hashtags on Twitter". Diakses pada 1 Juni 2016 dari http://www-personal.umich.edu/amazzia/pubs/ 545-final.pdf.

[6] Li T, Wu Y, Zhang Y. "Twitter Hash Tag Prediction Algorithm”. Diakses pada 1 Juni 2016 dari http://cerc.wvu.edu/download/WORLD COMP \%2711/2011\%20CD\%20papers/ICM333 8.pdf.

[7] Muhyi, Y., "Rekomendasi Hashtag Untuk Tweet Berbahasa Indonesia", Indonesia: STMIK Nusa Mandiri, 2016.

[8] Semiocast. "Twitter Reaches Half a Billion Accounts". Diakses pada 1 Juni 2016 dari http://semiocast.com/en/publications/2012_07_3 0_Twitter_reaches_half_a_billion_accounts_140 m_in_the_US.

[9] Sedhai, S., Sun, A., "Effect of Spam on Hashtag Recommendation for Tweets", Canada: 25th World Wide Web Conference, 2016.

[10] Sedhai, S., Sun, A., "HSpam14: A Collection of 14 Million Tweets for Hashtag-Oriented Spam Research", The 38th International ACM SIGIR Conference, 2015.

[11] Twitter. "How to Choose a Tag". Diakses pada 1 Juni 2016 dari https://blog.twitter.com/2013/ how-to-choose-a-hashtag.

[12] Zangerle, E., Gassler, W., Specht, G., "Recommending \#-Tags in Twitter. Proceedings of the Workshop on Semantic Adaptive Social Web 2011", http://ceur-ws.org, 2011. 